\title{
Código de Defesa do Consumidor e Mercosul: Vicissitudes em sua Coexistência
}

\section{Consumer's Defense Code and MERCOSUL: \\ Variations in their coexistence}

Fagner Gomes da Silva*

\section{Resumo}

Com o processo desencadeado pela conjuntura Pós-Guerra Fria, em que se observa a evolução da integração econômica e da realidade comunitária, evidencia-se a problemática da aproximação, harmonização e unificação das estruturas normativa dos Estados, muitas vezes em detrimento da legislação nacional e em favor do aprimoramento do bloco. O estudo, tomando como seu objeto o Código de Defesa do Consumidor e o MERCOSUL, aponta para os escopos buscados e para as divergências existentes entre essas duas manifestações do mundo jurídico. O primeiro intenta salvaguardar o consumidor em sua vulnerabilidade e hipossuficiência, enquanto o segundo apresenta como finalidade a integração econômica entre os povos irmanados pela proximidade geográfica, no Cone Sul da América. O trabalho apresenta essas duas realidades intimamente relacionadas a partir da análise de seus respectivos surgimentos, do exame do desenvolvimento de cada um, bem como do curso em que se direcionam, chegando à conclusão do estágio atual das interações por eles estabelecidas ao final do artigo.

Palavras Chave: Código de Defesa do Consumidor; MERCOSUL; Harmonização Legislativa; Possibilidade de Coexistência

\begin{abstract}
With the process created by the Cold War conjunction, in which the evolution of economic integration and communitarian reality are noticed, there is evidence of the problematic of becoming closer, the harmonization and unification of the legal structures of the States, often to the detriment of the development of the block. The study, having as its object the Consumer's Defense Code and MERCOSUL, points to the intended goals and to the differences, which exist between these two manifestations of the juridical word. The first one aims at protecting consumers in their vulnerability and hypo-sufficiency, whereas the second one presents as goal the economic integration among the peoples gathered by the geographical proximity, in the Southern Cone. The work presents these two realities closely related from the analysis of their respective origins, from the exam of the development of each one, as well as of the course that they are led, reaching the present stage of the relations established by them at the end of the article.
\end{abstract}

Key Words: Consumer's Defense Code; MERCOSUL; Harmonization of the Laws; Possibility of Coexistence

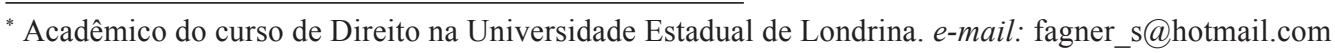




\section{Introdução}

Dois fenômenos da contemporaneidade completam dez anos; o Código de Defesa do Consumidor e o MERCOSUL. Eles denotam alterações significativas no status quo da conjuntura hodierna. O primeiro, no concernente às mudanças de direcionamento na regulamentação das relações de consumo; enquanto o segundo, no que tange à tendência de integração entre os povos, tanto em sentido econômico como jurídico-político.

O Código de Defesa do Consumidor representa uma grande mudança de perspectiva na protetividade do ente mais frágil da relação de consumo, isso em oposição às legislações de Direito Privado tidas pela doutrina como tradicionais.

O MERCOSUL, com a evolução institucional que vem apresentando, mostra-se como grande opção para os povos irmanados pela proximidade à Bacia do Prata neste período de globalização econômica, produzindo assim inúmeros efeitos no mundo jurídico.

Nota-se, quando analisado de plano, que o estágio avançado de protetividade alcançado por um membro do bloco em relação aos outros pode acarretar certa dissonância nas relações comerciais efetuadas intrabloco, o que será alvo de maiores considerações no corpo do texto.

Observando os possíveis choques entre interesses tutelados pelos dois elementos em debate, o trabalho procura tecer considerações pertinentes a partir de pesquisa doutrinária e legislativa, no que se refere aos efeitos desses embates na conjuntura vigente.

\section{Análises sobre o código de defesa do consu- midor brasileiro (c.d.c.)}

A partir da concepção kelseniana do Direito, ordem coercitiva da conduta humana fulcrada no pressuposto de existência de uma norma fundamental (KELSEN, 1985, p.36-54), ou baseado no Culturalismo jurídico de Miguel Reale, realização ordenada e garantida do bem comum numa estrutura tridimensional bilateral atributiva (REALE, 1988, p.67), observamos sempre a adequação do ordenamento jurídico positivo aos valores sociais dominantes em determinado período (ALMEIDA, 1982, p.11).

A produção legislativa pós-Revolução Francesa, principalmente na seara do Direito Privado, mostrase como reflexo do Liberalismo Clássico, de cunho antiabsolutista, vigente à época. Isso é facilmente demonstrado pela presença da filosofia liberal nos Códigos Civil e Comercial brasileiros, donde emergem, demasiadamente arraigadas, a proteção à iniciativa privada, à propriedade e aos direitos de credor.

Almeida (1982, p.12-24) caracteriza a ordem jurídica liberal a partir de dois princípios elementares, a Liberdade e a Igualdade, ideais mormente presentes no período revolucionário.

A Liberdade, enquanto conceito de fundamentação da ordem jurídica liberal, desdobra-se em três elementos: a) Autonomia da vontade, que consiste no princípio pelo qual ao elemento volitivo se faculta o poder de criação de direitos e de contrair obrigações; b) Efeito relativo, conhecido também como privacy of contract, que se refere à obrigatoriedade do cumprimento do nexum juris estabelecido pelas partes, contractus ex conventione partium legem accipiunt; c) Responsabilidade por culpa, à parte que, mesmo agindo de boa-fé, causar dano a outrem responde pelo prejuízo através do ressarcimento.

A Igualdade se desdobra em dois caracteres: a) Igualdade abstrata ou formal, que consiste na presunção de equiparação, no que concerne à faculdade de exposição do elemento volitivo, das partes que efetivam relação obrigacional; b) Desigualdade abstrata, estabelecimento de situações suscetíveis de desequiparação, das quais apenas a parte amparada por suporte técnico pode alcançar.

Denotando o declínio do modelo liberal na produção legislativa, em especial no que se refere ao princípio da igualdade contratual, e tendo o contrato 
como forma principal de exteriorização e implementação das operações econômicas, assevera Theodoro Júnior (2000, p.8):

[...] Falso também é o princípio da igualdade de todos na prática dos contratos. Os contratantes, em grande número de vezes e até na maioria das vezes, encontram-se em posições de notório desequilíbrio, seja moral, seja econômico, seja técnico, seja mesmo de compreensão e discernimento.

Consentâneo aos ensinamentos de Hobsbawm (1995, p.113-143), a crise do modelo liberal, deflagrada na terceira década do século XX, tem como sua causa principal a incapacidade deste sistema de suprir as necessidades e expectativas dos indivíduos em interação com os meios de produção inseridos no sistema capitalista. Essa crise culmina, quando analisada de uma perspectiva histórica, com a Depressão de 1929 juntamente com a formação de sistemas de governo antidemocráticos e antiliberais, verbi gratia, os Estados Fascistas e Socialistas, ambos arquétipos totalitários e corporativos de sistema político. Outro aspecto que denota mudança no sistema é o fenômeno do consumismo, elemento qualificado pelo dinamismo imprimido pela economia de massa contemporânea, pelo aumento no volume de transações comerciais, bem como sua múltipla variação, e pela publicidade comercial, um mecanismo de mercados de bens e serviços (CENEVIVA, 1991, p.19-26).

Nos dizeres de Ceneviva (1991, p.20) :

Os velhos códigos filiaram-se à concepção estática da economia, com base na propriedade privada (sendo preponderante a imobiliária), com o correspondente direito de usar, gozar e dispor dela, enquanto elemento fundamental da circulação e do aproveitamento de riqueza. As novas regras de mercado reclamam leis compatíveis com a agilidade das transações e o tráfego negocial baseado no consumo de milhares de itens e de serviços (a alienação fiduciária, por exemplo), assinados, em certos casos, por mecanismos internacionais inovadores (franchising, leasing são dois exemplos).
Acompanhando o colapso enfrentado pelo modelo político liberal clássico, o ordenamento jurídico apresenta mudanças no direcionamento, dimensionando-se a uma praxe mais acorde com o fenômeno social. O Direito Consumerista, na preferência denominativa da doutrina portuguesa, ou do Consumidor, no uso da literatura nacional, está relacionado a esse redimensionamento jurídico e visa a proteger o consumidor, este designado como parte vulnerável, e por muitas vezes hipossuficiente, na relação de consumo.

Em oposição aos princípios liberais de direito privado, foram erigidos fundamentos teóricos para abalizarem esse novo ramo do Direito (ALMEIDA, 1982, p.13-24): a) Princípio do Dirigismo estatal, o qual surge em oposição à autonomia da vontade $\mathrm{e}$ consagra a primazia da vontade coletiva em relação à vontade individual; b) Princípio da inversão do ônus da prova, elemento que protege o consumidor enquanto ente dotado de vulnerabilidade; c) Vontade real do consumidor é o princípio que tenciona perquirir da verdadeira intenção do consumidor no ato de contratar, e é observado principalmente nos contratos de adesão.

O desenvolvimento de legislação de caráter efetivamente protetivo, em âmbito nacional, tem seu desenvolvimento maior com a promulgação do Código de Defesa do Consumidor (Lei 8078, de 11 de setembro de 1990), diploma este que encerra a quintessência da técnica jurídica concernente à regulamentação das relações de consumo, mesmo que se possa notar movimentos nesse sentido desde de 1985, como no VI Congresso do Ministério Público (GRINOVER, 1998, p.23).

O Código de Defesa do Consumidor apresenta três caracteres especiais que o singularizam dentro do corpo legislativo brasileiro: a) Base constitucional, tem seu fundamento de validade decorrente de dispositivo existente na própria Constituição Federal, onde encontramos em seu artigo $5^{\circ}$, inciso XXXII e em seu artigo 48 das Disposições Transitórias, a determinação de elaboração de um corpo codificado 
que protegeria os interesses dos consumidores (GRINOVER, 1998); b) Estrutura microssistemática ${ }^{1}$, o legislador nacional, de acordo com Nery Junior (apud GRINOVER, 2000, p.430), desenvolve um microssistema de Direito das Relações de Consumo, forjando-se a partir de inúmeros elementos dos diversos ramos jurídicos existentes, tanto de Direito Material (Constitucional, Administrativo, Penal e Civil), como Instrumental (Civil, Administrativo e Penal); c) Estrutura de Código, definida constitucionalmente, que se baseia numa construção sistemática e principiológica, possibilita ao destinatário da norma e ao seu aplicador seu melhor manuseio, bem como maior homogeneidade (GRINOVER, 2000, p.8-9).

O C.D.C., a partir do que ensina Prux (1998, p.147-157), positiva oito princípios fundamentais, dentre os quais se destacam:

a) Princípio da vulnerabilidade do consumidor no mercado; o consumidor, figurante do pólo menos privilegiado da relação de consumo, tem presumidamente esta condição em razão de não ter formação técnica, no caso da utilização de serviços se comparado ao fornecedor, tampouco conhecimentos específicos, no caso da aquisição de produtos;

b) Princípio da educação e da informação; na busca da harmonização, tem-se a necessidade de pulverização das informações no seio da sociedade civil, bem como a formação de consumidores conscientes por meio do processo educacional, responsabilidade esta que não esta circunscrita à competência do Estado, mas de toda a comunidade;

c) Qualidade efetiva dos produtos ou serviços; de acordo com Filomeno (1999), tem estrita ligação com uma característica subjetiva, a 'satisfação de seus consumidores', concatenando a necessida- de de cuidado do consumidor por parte do fornecedor;

d) Coibição dos abusos de mercado; princípio que esclarece ser a intenção da norma protetiva abranger não somente o resguardo dos direitos dos consumidores, mas também dos fornecedores em situação de menor vantagem econômica em relação aos controladores do mercado e consumo;

e) Racionalização na melhoria dos serviços públicos; exigir dos serviços públicos as mesmas obrigações requeridas da iniciativa privada no que concernir à proteção e defesa do consumidor. Cabendo também relevância aos princípios: da autorização para ação governamental; da harmonização das relações de consumo; e do estudo constante das modificações do Mercado.

Com a introdução positiva dos princípios suprareferidos no ordenamento jurídico brasileiro, pela Lei 8078/90, o mercado teve de se conformar com a nova sistemática concernente à política de consumo adotada pelo Brasil. Pelo que ressalta Filomeno (1999, p.73), de acordo com o Jornal O Estado de São Paulo, de 4 de maio de 1998, o Brasil se encontra na segunda posição entre os países que perseguem a qualidade total através do método da ISO 9000, isso devido a grande assimilação do operariado brasileiro das novas técnicas.

\subsection{Da Relação de Consumo}

Tendo, assim como José Geraldo Filomeno, as relações de consumo como "relações jurídicas por excelência, pressupondo, por conseguinte, dois pólos de interesse: o consumidor-fornecedor e a coisa, objeto desses interesses" (GRINOVER, 2000, p.42), faz-se necessário o tratamento de cada elemento dessa relação.

${ }^{1}$ Como diz Orlando GOMES (1983, p. 47), acerca das leis especiais:

[...] não são desdobramentos de institutos codificados, não regulam matéria estranha aos conteúdos de direito privado, nem apanham menor número de destinatários ou de hipóteses, até porque, como observou alguém, o seu consumo é maior do que o dos artigos do Código Civil. Constituem 'distintos universos legislativos', de menor porte, denominados por um autor com muita propriedade, micro-sistemas. 
"O conceito de relação jurídica é um dos conceitos fundamentais [...]. Não é um conceito só específico do direito privado, ou só específico do direito público; atravessa universalmente todos os subdomínios do direito positivo" (VILANOVA, 2000, p.114), sendo conceituado pela doutrina tradicional como "uma relação entre dois sujeitos, constituída pelo direito, concernente a um objeto" (CARNELUTTI, 1999, p.184).

Os elementos constituintes da relação de consumo, ou seja, aquelas relações que estão submetidas ao regime instituído pela lei 8078/90, segundo a doutrina de Nelson Nery Júnior (apud GRINOVER, 2000, p.430-472), são formados por três elementos: sujeitos, os quais seriam consumidor e fornecedor; objeto, tendo-se produtos e prestação de serviços; e, finalidade de utilização com destinação final.

\subsection{Elemento Subjetivo da Relação de Consumo}

No que tange ao seu elemento subjetivo, a relação de consumo se perfaz na antagonização de dois pólos, os quais se consubstanciam em consumidor e fornecedor.

O C.D.C. ${ }^{2}$, em seu art. $2^{\circ}$, encerra o conceito de consumidor considerando, do ponto de vista econômico, o indivíduo inserido no mercado de consumo no que tange à atenção de suas necessidades pessoais, diversamente das de cunho empresarial.

Do conceito fornecido pela lei 8078/90, nasce a problemática da abrangência da aplicabilidade da norma protetiva quanto ao sujeito vulnerável da relação. De acordo com Cláudia Lima Marques (1999, p.141, 152), a discussão deu origem a duas correntes: os "finalistas" e os "maximalistas".

Os finalistas defendem a aplicabilidade das normas contidas no sistema definido pelo C.D.C. apenas àqueles que qualificados como "destinatário fático e econômico do bem ou serviço", ou seja, a partir de uma interpretação restritiva do conceito de consumidor.

Assim assevera Cláudia Lima Marques (1999, p.142):

Logo, segundo esta interpretação teleológica não basta ser destinatário fático do produto, retira-lo da cadeia de produção, leva-lo para o escritório ou residência, é necessário ser destinatário final econômico do bem, não adquiri-lo para a revenda, na adquiri-lo pra uso profissional, pois o bem seria novamente um instrumento de produção cujo preço será incluído no preço final do profissional que adquiriu. Neste caso não haveria a exigida destinação final do produto ou serviço.

De forma diversa, os maximalistas entendem as normas positivadas pelo C.D.C. como novo regulador do mercado de consumo nacional, desate, seria o C.D.C. um diploma legal que instituiria limites normativos para todos os partícipes do mercado, os quais ocupariam comutativamente os papéis de consumidor e fornecedor, sendo a destinação final do produto ou serviço compreendida de forma extensiva, incluindo os bens de produção como de destino final.

Tem logrado maior êxito na doutrina contemporânea brasileira a corrente defendida pelos finalistas, sendo consumidor quem "adquirir ou utilizar-se de um produto ou serviço como destinatário final, ou seja, como sujeito que retira o objeto do mercado de consumo, para uso próprio ou familiar, encerrando, desse modo a cadeia econômica de consumo" (LISBOA, 2000, p.300).

No que se refere à qualificação do outro pólo da relação de consumo, o fornecedor, o artigo $3^{\circ}$ do C.D.C. ${ }^{3}$ explicita seu conteúdo de forma expansiva,

${ }^{2}$ Art. $2^{\circ}$ do Código de Defesa do Consumidor: "Consumidor é toda pessoa física ou jurídica que adquire utiliza produto ou serviço como destinatário final".

${ }^{3}$ Art. $3^{\circ}$ do Código de Defesa do Consumidor: "Fornecedor é toda pessoa física ou jurídica, pública ou privada, nacional ou estrangeira, bem como entes despersonalizados, que desenvolvem atividades de produção, montagem, criação, construção, transformação, importação, exportação, distribuição ou comercialização de produtos ou prestação de serviços". 
não restringindo nacionalidade (nacional ou estrangeira), regime jurídico a que está submetido (direito público ou privado), nem personalidade jurídica (pessoa física, jurídica e entes despersonalizados).

De acordo com Plácido e Silva, o verbete fornecedor é "derivado do francês fournir (fornecer, prover), de que se compôs fournisseur (fornecedor)" (SILVA, 1999a), tendo a doutrina mencionado três categorias clássicas de fornecedores (GRINOVER, 2000, p.158): "fornecedor real", compreendendo aqueles ligados diretamente à atividade produtiva, v.g. o fabricante, o produtor e construtor; "fornecedor presumido", tendo o importador de produtos industrializados ou in natura como figurante nessa categoria; e ao final, "fornecedor aparente", ou seja, aquele que apõe seu nome ou marca no produto final, isso em razão de proceder certo tipo beneficiamento no produto comercializado.

No que tange às atividades empreendidas pelo fornecedor e elencadas na lei de tutela os consumidores, pode-se afirmar seu caráter exemplificativo e sugestivo, podendo outras atividades não especificadas no texto legal serem caracterizadas como atividade típica de fornecedores.

Assim para o Direito do Consumidor entende-se por fornecedor "todo aquele que não adquiri, como destinatário final, um produto ou um serviço, porém o transfere a outrem no próprio mercado de consumo" (LISBOA, 2000, p.300), toda aquele responsável pela disponibilização de produtos ou serviços em favor do consumidor.

No que concerne aos protagonistas da relação jurídica de consumo, pode-se dizer que "aos novos direitos dos consumidores correspondem sempre, na metodologia do Código de Defesa do Consumidor, novos deveres para os fornecedores de bens e serviços" (MARQUES, 1999, p.42).

\section{Elemento Objetivo da Relação de Consumo}

Os parágrafos $1^{\circ}$ e $2^{\circ}$, artigo $3^{\circ}$, C.D.C. ${ }^{4}$, descrevem qual seriam os elementos passíveis de figurar na relação jurídica de consumo como objeto, os quais são: Produtos e Serviços.

Produto, na lição de Roberto Senise Lisboa (2000, p.300-301), "é qualquer bem suscetível e valoração econômica, pouco importando a classificação a ser adotada [...]. Basta que esteja disponível à aquisição, isto é, seja res commercio".

O constante do $\S 1^{\circ}$, do artigo $3^{\circ}$, C.D.C., elucida com clareza que o essencial do conceito não reside na sua compleição física, material ou imaterial, nem na sua característica de locomoção (móvel ou imóvel), possibilitando a interpretação de seu conteúdo de onerosidade, ou seja, fazer parte de relação de consumo com fins econômicos.

Serviços, outro elemento objetivo da relação jurídica de consumo, são considerados quaisquer "atividades, benefícios ou satisfações que são oferecidos à venda" (GRINOVER, 2000, p.44), o que cabe perfeitamente na conceituação emitida pelo dispositivo legal contido no §2], artigo $3^{\circ}$, C.D.C.

\subsection{Elemento Teleológico da Relação de Consumo}

O elemento finalístico da relação jurídica de consumo consiste no fato de ser o produto ou serviço que adentra a esfera patrimonial do consumidor de "destinação final", ou seja, o fim buscado pelo adquirente de determinado produto ou utilizador de determinado serviço necessariamente tem de ser encarado como o patamar final dentro da cadeia produtiva econômica.

"A chave para a identificação de uma relação jurídica como sendo de consumo é, portanto, o elemento teleológico: destinação final, ao consumidor, do produto ou serviço" (GRINOVER, 2000, p.472).

\footnotetext{
${ }^{4}$ Artigo $3^{\circ}, \S 1^{\circ}$. "Produto é qualquer bem, móvel ou imóvel, material ou imaterial".

Artigo $3^{\circ}, \S 2^{\circ}$. "Serviço é qualquer atividade fornecida no mercado de consumo, mediante remuneração, inclusive as de natureza bancária, financeira, de crédito e securitária, salvo as decorrentes das relações de caráter trabalhista”.
} 


\section{A experiência do mercado comum do sul (MERCOSUL)}

A realidade do MERCOSUL, organização internacional de alcance regional e com finalidade específica de integração econômica (REZEK, 1988, p.267), inserida na conjuntura econômica do PósGuerra que viabilizou a reunião de Estados soberanos em blocos econômicos, fundamenta-se cientificamente na teoria de integração econômica, apresenta como objetivo construir um mercado comum a partir de seu surgimento datado na assinatura do Tratado de Assunção, em 26.03.1991, e completa dez anos de existência.

A teoria da integração (CARVALHO, 2000, p.232), objeto de estudo das Ciências Econômicas, utiliza-se de quatro proposições elementares para fulcrar o fenômeno dos agrupamentos de países em blocos econômicos, quais sejam:

a) Aproveitamento das vantagens comparativas regionais: teoria proposta por David Ricardo (apud HUNT, 1981, p.137), que propõe a utilização otimizada das potencialidades características de cada país partícipe da relação de comércio internacional, propiciando, deste modo, maior especialização na produção de bens com menor custo unitário. A partir disto, cada ente internacional, aproveitando melhor suas características naturais e sociais, produziria determinados bens com maior eficiência, ao passo que, consumiria produtos distintos produzidos pelos seus parceiros comerciais. Surgido, destarte, a complementaridade industrial com lucro para o conjunto;

b) Criação de economia de escala: a criação de economia de escala consiste na diminuição do custo final do produto através da produção massificada (BATISTI, 1998, p.29). O custo unitário final do produto é composto por uma parte fixa, que independe do montante da produção, e uma variável, que a acompanha proporcionalmente ao seu crescimento. Isto posto, temos que quanto maior a produção, maiores serão os custos variáveis em valores absolutos e constantes em termos relativos, enquanto os custos fixos se mantêm constantes em valores absolutos e cada vez menores em valores relativos. Quanto mais produzir determinado ente econômico, proporcionalmente menores serão seus custos fixos, o que ocasionará menor custo unitário final (custo unitário final = custo fixo + custo variável);

c) A possibilidade de oferta de maior variabilidade de produtos deriva, como efeito da criação de economia de escala unida ao aproveitamento das vantagens comparativas, num mercado maior, por exemplo, o criado pela união aduaneira que implica numa maior quantidade de bens, produzidos com maior eficiência oferecidos pelos entes participantes da parceria comercial;

d) Maior concorrência intra-regional, a ampliação do mercado também gera o aumento da concorrência intra-regional, propiciando, desse modo, a busca de melhor produtividade, melhor investimento de recursos e menor preço para o consumidor final.

O desenvolvimento histórico do MERCOSUL, bloco econômico que abriga como seus membros o Brasil, a Argentina, o Paraguai e o Uruguai, tem seu marco inicial com a assinatura do Tratado de Assunção. Tratado que em seu artigo primeiro define o objetivo do bloco, qual seja, formar um mercado comum através do estabelecimento de uma tarifa externa comum, estímulo da livre circulação de bens, serviços e fatores produtivos, coordenação de políticas macroeconômicas e setoriais e harmonização de suas legislações no que pertencer ao processo de integração.

O Tratado de Assunção e a Convenção BENELUX ${ }^{5}$ mantêm nítidas semelhanças, visto que ambos procuram integração puramente econômica,

${ }^{5}$ Acordo Internacional que estabelece a União Aduaneira entre Bélgica, Holanda e Luxemburgo. 
prezando destarte pelo conceito de intergovernamentabilidade, diferentemente do Tratado de Roma que institui órgãos de administração supranacional (GONÇALVES, 1998, p.90).

O MERCOSUL é composto, conforme consolidação efetuada pelo Protocolo de Ouro Preto, de 1994: por um Conselho do Mercado Comum, órgão superior de decisão composto pelos ministros das Relações Exteriores e os ministros da Economia dos países-membros; pelo Grupo Mercado Comum, órgão de caráter executivo que procura velar pelo cumprimento do tratado e das decisões do Conselho, sem olvidar a obrigação de formação de dez subgrupos de trabalho para tratar de temas específicos; Comissão de Comércio do MERCOSUL, órgão competente para assistir o Grupo Mercado Comum em matéria de relação comercial, donde se extrai o Comitê Técnico n. 7, a quem foi confiado o dever de harmonizar as legislações concernentes ao Direito do Consumidor (BATISTI, 1998, p.419), isso com o auxilio da Secretaria de Administração e da Comissão Parlamentar Conjunta.

Nos dez anos de integração econômica e vicissitudes enfrentadas pelo MERCOSUL, podem-se visualizar as fases de integração percorridas por ele: Zona de Livre Comércio e União Aduaneira (no momento imperfeita).

Da assinatura do Tratado de Assunção até 1994, o MERCOSUL atravessou a zona de livre comércio se preocupando em remover os óbices à livre circulação de produtos, primeiro utilizando-se de um programa de redução gradual das tarifas alfandegárias, depois aplicando uma política para a eliminação das barreiras não tarifárias de forma progressiva. Em 1994, com a adoção de uma Tarifa Externa Comum, em Buenos Aires, o Mercado Comum do Sul evolui de zona de livre comércio para uma união aduaneira, no momento imperfeita, em que se procura harmonização nas relações econômicas e adequação à concorrência, levando-se em conta as particularidades e as deficiências produtivas existentes entre os signatários do Tratado de Assunção. É nesta situação que se encontra o bloco atualmente.
Concordando com Cláudia Lima Marques (1997, p.82-83), o MERCOSUL denota, devido à típica característica de fenômeno comercial, uma hipertrofia em seu aspecto econômico em comparação a seu elemento jurídico-político, deixando destoar a natural discrepância de desenvolvimentos entre estas duas faces de uma mesma realidade.

Findo o amadurecimento do MERCOSUL, previsto para 2006, forjar-se-á a primeira experiência de um mercado comum com vistas a propiciar livre comércio, política comercial uniforme, livre movimentação de fatores de produção e aproximação das políticas regionais no Cone Sul (GONÇALVES, p.1998, p.235-236).

\section{Possível conflito entre código de defesa do consumidor e Mercosul}

Pode-se, num primeiro momento, encontrar discrepâncias nos objetivos procurados pelos Código de Defesa do Consumidor e MERCOSUL, mas logo se percebe o engano perpetrado.

Desta forma, no âmbito do MERCOSUL, como salienta Batisti (1998, p.533), “um Regulamento Comum sobre a Defesa do Consumidor atua no sentido de manter essa igualdade para a competição, sem o que não poderá falar em Mercado Comum. Necessário que regras homogenias quanto à garantia, quanto aos riscos, quanto à publicidade, etc"

A regulamentação das relações de consumo pode ser relacionada ao estímulo ou impedimento aos fluxos das transações comerciais efetuadas entre os Estados, isso se a considerarmos qual uma barreira técnica para entrada de produtos no mercado interno que assentar maior ou menor número de exigências no aperfeiçoamento da qualidade dos produtos e serviços passíveis de lhe serem introduzidos. Sabe-se, hodiernamente, que o arrolamento de requisitos na busca da qualidade não deve ser visto por este prisma, haja vista que o aprimoramento do objeto da prestação nas relações de consumo promove o bem estar da comunidade geral, tanto do ponto de vista 
do consumidor satisfeito com o produto ou serviço quanto do panorama integracionista, que estimula a competitividade do bloco.

Sobre o Direito Consumerista no âmbito do MERCOSUL, pode-se afirmar que foi um interesse nascido da preocupação com o consumidor, diferentemente o que ocorreu na União Européia, em que se nota como mola propulsora da discussão a preocupação com o combate à concorrência desleal. $\mathrm{Na}$ União Européia, havia quem percebesse na defesa do consumidor um meio de barreira a entrada de bens e serviços aos seus mercados internos, ou seja, quanto maior a carga de protetividade menor o fluxo de importação. Esse raciocínio se encontra defasado atualmente.

No MERCOSUL, pode-se distinguir quatro fases no caminho percorrido para a aproximação das legislações consumeristas (MARQUES, 1999, p.2025): Primeira fase, não se pode notar uma preocupação ostensiva com o assunto até que se efetuou, em 1996, a Reunião de Ministros de Justiça do Mercosul, o que ocasionou numa maior discussão do tema; Segunda fase, com a instituição de uma Comissión de Estudios de Derecho del Consumidor, o Subgrupo n. 10 do Grupo de Mercado Comum começa os trabalhos de harmonização legislativa; Terceira fase, a comissão de estudos passa-se a chamar Comitê Técnico n. 7, a qual propõe uma verdadeira unificação legislativa no âmbito do Direito do Consumidor, na forma de um Protocolo comum em 1997, que viria revogar os dispositivos da legislação nacional e representar verdadeiro retrocesso no desenvolvimento da proteção do consumidor para a realidade brasileira; Quarta fase, o Comitê Técnico n. 7 opta por estabelecer regramentos mínimos ${ }^{6}$, não impedindo maior ou menor possibilidade de proteção pelos Estados-Membros do mercado.

Como assevera Frederico A. M. Simionato (BASSO, 1997, p.137), a característica institucional do MERCOSUL não permite a aplicação direta das normas por ele emanadas, as quais necessitam do elemento volitivo de cada participante do bloco na direção da aceitação da nova norma elaborada.

Isso conserva estreita correlação com as observações de Ventura (1996, p.114), em que ela assevera:

A eficácia dos fatos gerados pelas regras atinentes ao MERCOSUL dependem, portanto, da vontade (Estados, empresas e cidadãos) de materializa-las. Este componente determina a instabilidade destas relações, atributo que se multiplicarão com o aprofundamento do processo integracionista.

Não obstante a necessidade de aproximação das legislações dos Estados membros do bloco mercosulino, observa-se a impraticabilidade de processo de uniformização dirigida (DOLINGER, 2001, p.36) nas referidas legislações, incluindo-se nesse grupo as relações de consumo, visto que, mesmo que se consiga uniformizar o Direito do Consumidor, a consubstanciação das regras jurídicas abstratas requer intervenção dos tribunais nacionais, permitindo-se margem a interpretações díspares do mesmo texto legal conforme o nível de protetividade alcançado por cada ordem jurídica, a qual é movimentada pelos órgãos jurisdicionais de cada nacionalidade.

Outro fator importante quanto à caracterização do Direito do Consumidor no MERCOSUL consiste no fato daquele fazer parte do rol dos Direitos Humanos de terceira Geração e ter fulcro na Constituição Federal.

Os Direitos Humanos de Terceira Geração ou Direitos de Solidariedade, entre os quais se aloca o Direito do Consumidor, como averba Claudia Lima Marques (1997), estão intimamente ligados à qualidade de vida e à dependência recíproca entre as nações, como assevera Manuel Gonçalves Ferreira Filho (1998, p.57), o que não deixa de ter relação com

${ }^{6}$ Esses regramentos mínimos guardam estrita relação, do ponto de vista da abrangência e não do mecanismo de aplicabilidade, com as diretivas utilizadas no âmbito da União Européia. Segundo Cláudia Lima MARQUES (1997, p.300) as "diretivas são leis flexíveis, espécies de leis-modelos supranacionais, cuja incorporação nos ordenamentos nacionais é obrigatória para os países da união Européia. Note-se que obrigatório é seu objetivo [...], não sua forma ou método de sua internalização [...] 
a realidade representada pelo MERCOSUL, que do mesmo modo tem por intento a integração políticosocial-econômicas dos povos irmanados pelo Prata.

O fulcro constitucional está sobre três dispositivos principais: o artigo 5 , XXXII, que o insere entre os Direitos Individuais e Coletivos; artigo 150, § 5 , que lhe confere proteção entre as normas tributárias; artigo 170, que o elenca em meio aos princípios que dão fundamento a justiça social, assim como diz Cáio Tácito (apud GUSMÃO, 1992, p.13).

A dificuldade da redução do conteúdo da proteção dispensada à parte vulnerável da relação de consumo por meio de iniciativa do Comitê Técnico $\mathrm{n}$. 7 , no ordenamento jurídico brasileiro, encontra-se em diversos pontos: a classificação do Direito do Consumidor como Direitos Individuais de Terceira Geração, o que o coloca entre as cláusulas pétreas da Constituição, artigo 60, 4 ; seu embasamento constitucional suprareferido; a falta de representatividade do órgão produtor de normas do MERCOSUL, visto que sua composição é satisfeita, pelo menos em sua essência, pelo poder executivo e sem participação da sociedade civil ${ }^{7}$; o Tratado de Assunção, em seu Preâmbulo, incentiva o desenvolvimento das políticas de proteção do consumidor quando promove a melhoria da qualidade dos bens e serviços ${ }^{8}$; o mesmo diploma internacional marca o compromisso dos Estados partícipes do Mercado de harmonização de suas legislações, não de sua unificação?

Assim, nota-se o imperativo da aproximação legislativa via diretrizes mínimas, admitindo a cada país dilatar ou não sua proteção acordando com sua tradição jurídica e constatando que na realidade vivida pelo MERCOSUL "não há espaços para leis uniformes, a não ser que mínimas" (MARQUES, 1997, p.301).

\section{Conclusão}

O Código de Defesa do Consumidor brasileiro apresenta-se como diploma legal de grande valor para o ordenamento jurídico brasileiro. Tanto pelo desenvolvimento técnico-jurídico que ele condensa, sendo considerado modelo para o Mundo, quanto pelo nível alcançado no diz respeito à proteção dispensada ao consumidor.

O Tratado de Assunção oferece existência e o Protocolo de Ouro Preto institucionaliza o corpo operacional do MERCOSUL, o qual se firma despontando como melhor caminho para os países do Cone Sul se adaptarem à nova conjuntura econômica baseada em economia de escala, alto desenvolvimento no que se aludi à qualidade e produtividade, consumo em massa e aglutinação de Estados soberanos em blocos.

Nota-se a tendência do Mercado Comum do Sul, no que tange à harmonização legislativa em matéria de Direito do Consumidor, de elaborar diretrizes protetivas mínimas dando, assim, certa margem de liberdade para cada país estabelecer sua política de proteção do consumidor como melhor lhe aprouver dentro das limitações minimizadas.

Conclui-se que as divergências apontadas entre o Código de Defesa do Consumidor e o MERCOSUL foram superadas, dando espaço hoje à interpretação que concebe coexistência entre os dois entes. Isso em atenção ao melhor atendimento do consumidor, ao desenvolvimento social e econômico e ao estímulo à busca do bem comum, ideais que ambos procuram salvaguardar.

\footnotetext{
${ }^{7}$ Nas palavras de Haroldo Pabst (1998, p. 132):

"Do ponto de vista prático, a harmonização deve atender ainda ao requisito da ampla divulgação, com vistas na participação de toda sociedade no processo. O princípio da democracia não deve ser postergado sob pretexto de que apenas ações rápidas e autoritárias podem levar a integração jurídica a bom termo".

${ }^{8}$ Trecho do Preâmbulo do Trado de Assunção: "promover o desenvolvimento científico e tecnológico dos Estados-Partes e de modernizar suas economias para ampliar a oferta e a qualidade dos bens e serviços disponíveis, a fim de melhorar as condições de vida de seus habitantes".

${ }^{9}$ Tratado de Assunção, artigo 1 , "O compromisso dos Estados-Partes de harmonizar suas legislações, nas áreas pertinentes, para lograr o fortalecimento do processo de integração".
} 


\section{Bibliografia}

ALMEIDA, Carlos Ferreira de. Os Direitos dos Consumidores. Coimbra: Almedina, 1982.

BASSO, Maristela (Org.). MERCOSUL: Seus Efeitos Jurídicos, Econômicos e Políticos nos Estados-Membros. 2 ed. Porto Alegre: Livraria do Advogado, 1997.

BATISTI, Leonir. Direito do Consumidor para o MERCOSUL. 2.ed. Curitiba: Juruá, 1998.

CARNELUTTI, Francesco. Teoria Geral do Direito. Trad. Antonio Carlos Ferreira. São Paulo: Lejus, 1999.

CARVALHO, Maria Auxiliadora; SILVA, César Roberto Leite. Economia Internacional. São Paulo: Saraiva, 2000.

CENEVIVA, Walter. Publicidade e Direito do Consumidor. São Paulo: Revistas dos Tribunais, 1991.

DOLINGER, Jacob. Direito Internacional Privado: Parte Geral. 6.ed. Rio de Janeiro: Renovar, 2001.

FERREIRA FILHO, Manuel Gonçalves. Direitos Humanos Fundamentais. 2.ed. São Paulo: Saraiva, 1998.

FILOMENO, José Geraldo Brito.Manual de Direito do Consumidor. 3.ed. São Paulo: Atlas, 1999.

GOMES, Orlando. Novos Temas de Direito Civil. Rio de Janeiro: Forense, 1983.

GONÇALVES, Reinaldo et al. A Nova Economia Internacional: Uma Perspectiva Brasileira. Rio de Janeiro: Campus. 1998

GRINOVER, Ada Pellegrini et al.. Código Brasileiro de Defesa do Consumidor: Comentado pelos Autores do Anteprojeto. 6.ed. Rio de Janeiro: Forense Universitária, 2000.

GUSMÃO, Paulo Dourado; GLANS, Semy (Coord.). $O$ Direito na Década de 1990: Novos aspectos. São Paulo: Revista dos Tribunais, 1992.

HOBSBAWM, Eric, A Era dos Extremos: O Breve Século XX 1914-1991. 2.ed. Trad. Marcos Santarrita. São Paulo: Companhia das Letras, 1995.

HUNT, E. K. História do Pensamento Econômico. 7.ed. Trad. José Ricardo Brandão Azevedo. Rio de Janeiro: Campus. 1981

KELSEN, Hans. Teoria Pura do Direito. Trad. João Baptista Machado. São Paulo: Martins Fontes, 1985.

LISBOA, Roberto Senise. Contratos Difusos e Coletivos: consumidor, meio ambiente, trabalho, agrário, locação, autor. $2^{\mathrm{a}}$ ed. São Paulo: Revista dos Tribunais, 2000.

MARQUES, Cláudia Lima. Direitos do Consumidor: algumas sugestões frente ao impasse. Revista de Direito do Consumidor, São Paulo: Revista dos Tribunais, n.32, p.16-44, out. /dez. 1999.
Contratos de Defesa do Consumidor: o novo regime das relações de consumo. 3.ed. São Paulo: Revista dos Tribunais, 1998.

Regulamento Comum de Defesa do Consumidor do MERCOSUL: Primeiras Observações Sobre o MERCOSUL Como Legislador da Proteção do Consumidor. Revista de Direito do Consumidor. São Paulo, n.23, p.79-103, jul. /dez. 1997.

União Européia Legisla Sobre Cláusulas Abusivas: um exemplo para o MERCOSUL. Revista de Direito do Consumidor. São Paulo, n.21, p.300-310, jan/ mar. 1997.

Novas Regras Sobre a Proteção do consumidor nas Relações Contratuais. Revista de Direito do Consumidor. São Paulo, n.1, p.27-54, mar., 1992.

PABST, Haroldo. MERCOSUL: Direito da Integração. Rio de Janeiro: Forense, 1998.

PRUX, Oscar Ivan. Responsabilidade Civil do Profissional Liberal no Código de Defesa do Consumidor. Belo Horizonte: Del Rey, 1998.

REALE, Miguel. Lições Preliminares de Direito. 24.ed. São Paulo: Saraiva, 1998.

REZEK, José Francisco. Direito Internacional Público: Curso Elementar. 7.ed. São Paulo: Saraiva, 1998.

SILVA, De Plácido e. Vocabulário Jurídico. Atual. Geraldo Magela Alves \& Nagibi Islaib Filho. 15.ed. Rio de Janeiro: Forense, 1999. cd-rom.

SILVA, Roberto Luiz. Direito Comunitário e de Integração. Porto Alegre: Síntese, 1999.

THEODORO JÚNIOR, Humberto. Direitos do Consumidor: a busca de um ponto de equilíbrio entre as garantias do Código de defesa do Consumidor e os princípios gerais do direito civil e do direito processual civil. 2.ed. Rio de Janeiro: Forense, 2001.

VENTURA, Deisy de Freitas Lima. A Ordem Jurídica do MERCOSUL. Porto Alegre: Livraria do Advogado, 1996.

VILANOVA, Lourival. Causalidade e Relação no Direito. 4.ed. São Paulo: Revista dos Tribunais, 2000.

\section{Agradecimentos}

Gostaria de agradecer à Professora Mestre Heloísa Helena de Almeida Portugal pela orientação e encaminhamento na feitura deste trabalho, ainda, gostaria de estender meus agradecimentos à Professora Doutora Maria de Fátima Ribeiro pelo auxílio e discussões junto às reuniões do projeto de pesquisa O Imposto Sobre o Valor Agregado; seus efeitos no MERCOSUL. 
